\title{
Avaliação de métodos geofísicos aquáticos aplicados ao estudo de assoreamento na bacia do Córrego do Bananal, no Lago Paranoá - Brasília/DF.
}

Frederico Ricardo Ferreira Rodrigues de Oliveira e Sousa (frederico.oliveira@cprm.gov.br - CPRM); Kayque Bergamaschi Rodrigues Carneiro (kayquebrc@hotmail.com - RuralTech); Welitom Rodrigues Borges (welitom@unb.br - IG/UnB); Marco lanniruberto (ianniruberto@unb.br - IG/UnB)

Copyright 2014, SBGf - Sociedade Brasileira de Geofísica

Este texto foi preparado para a apresentação no VI Simpósio Brasileiro de Geofísica, Porto Alegre 14 a 16 de outubro de 2014. Seu conteúdo foi revisado pelo Comitê Pócto Alegre, 14 a 16 de outubro de 2014. Seu conteúdo foi revisado pelo Comite Técnico do VI SimBGf, mas não necessariamente representa a opinião da SBGf ou
de seus associados. É proibida a reprodução total ou parcial deste material para propósitos comerciais sem prévia autorização da SBGf.

\section{Resumo}

Este trabalho apresenta uma avaliação sobre a aplicabilidade de alguns métodos geofísicos aquáticos no estudo do assoreamento no Lago Paranoá, Brasília/DF. Foram utilizados os métodos sísmico, elétrico e eletromagnético em uma área de, aproximadamente, $0,20 \mathrm{~km}^{2}$, situada na região de descarga do Córrego Bananal, no Lago Paranoá. Os equipamentos utilizados foram: a) o ecobatímetro monofeixe de dupla frequência, que possibilitou a investigação da profundidade, sua variação em um período de 5 anos e a visualização da morfologia de fundo; b) o sonar de varredura lateral, cujos transdutores piezoelétricos operaram nas frequências de 100 e $500 \mathrm{kHz}$, que possibilitou a obtenção de imagens acústicas do assoalho lacustre com boa resolução; c) o perfilador (SBP), que operou na faixa de frequência de 2 a $16 \mathrm{kHz}$, mas não obteve boa penetração no meio; d) o eletrorresistivímetro, com cabos multieletrodo dos tipos anfíbio e aquático, conforme os arranjos Wenner, Schlumberger e Dipolo-dipolo. Seus resultados possibilitaram o imageamento do leito e da subsuperfície do lago até a profundidade 15 metros. $\mathrm{Na}$ margem do lago obtiveram-se leituras de até 25 metros com o caminhamento elétrico 2D; e) o radar de penetração de Solo (GPR) com antena blindada de 100 $\mathrm{MHz}$, o qual teve seu sinal atenuado tanto em virtude da presença de gás no sedimento quanto ao fato da presença de uma camada condutiva, também detectada com o eletrorresistivímetro. Os resultados possibilitaram uma classificação entre os métodos geofísicos utilizados, com vistas a eleger aqueles mais recomendados para 0 tipo de estudo ambiental em questão.

\section{Introdução}

Um dos principais fenômenos que ocasionam a queda no volume útil de reservatórios hídricos é o assoreamento . Estima-se que a perda anual de volume, devido ao assoreamento dos reservatórios brasileiros, é próxima de $0,5 \%$ ao ano (CARVALHO, 1994). Esse fenômeno natural, passível de aceleração pela ação antrópica, pode inviabilizar a operação de aproveitamento hidrelétrico e/ou abastecimento urbano, seja pela abrasão provocada pelos sedimentos nas máquinas (bombas, turbinas etc.), seja pela diminuição do volume útil do reservatório (ICOLD, 1989).

Os sedimentos que alcançam o lago são originários da área de influência de sua bacia hidrográfica e sua disponibilidade depende do processo de erosão e cobertura do solo. Essas partículas são transportadas pelos canais tributários, galerias de águas pluviais, estações de tratamento e via escoamento superficial (vide CARVALHO, 2000; SUGUIO, 2003; NICHOLS, 2009). As barragens geram uma redução no fluxo hídrico devido ao aumento da seção transversal do curso d'água, ocasionando perda na capacidade de transporte de partículas que acabam se depositando no leito.

Este trabalho dirige a sua atenção para o Lago Paranoá, situado em Brasília-DF (figura 1).

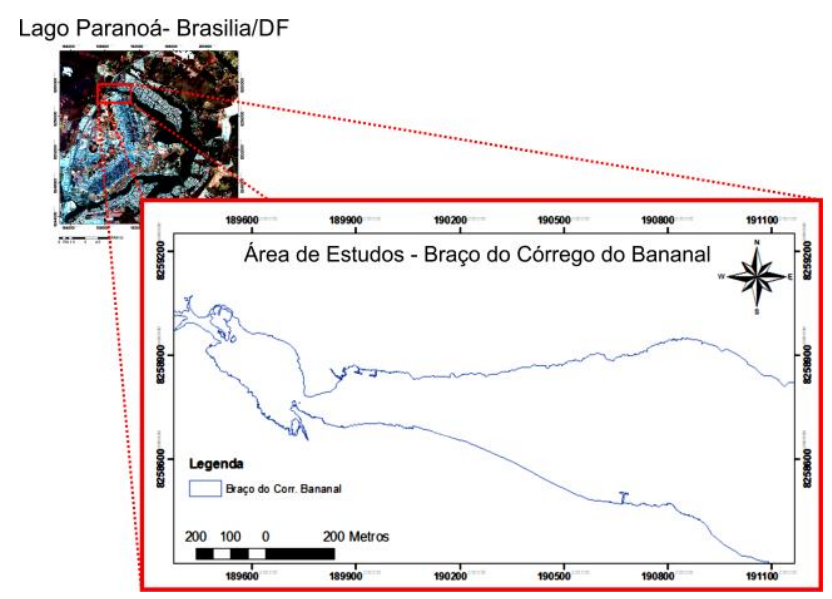

Figura 1 - Área de estudos, localizada na parte norte do Lago Paranoá, em Brasília/DF.

Em relação à cota de $1000 \mathrm{~m}$, estima-se que o lago inteiro armazene cerca de $560 \times 10^{8} \mathrm{~m}^{3}$ de água, ocupando uma área de $39,48 \mathrm{~km}^{2}$ de área (CAESB, 2003), o que proporciona um volume útil de, aproximadamente, $53,05 \times 10^{8} \mathrm{~m}^{3}$ (ADASA, 2012) para geração de energia elétrica e abastecimento urbano.

Segundo Menezes (2010), no Lago Paranoá, o fenômeno do assoreamento está fortemente associado ao uso e ocupação de solos na área de influência de sua bacia hidrográfica. A construção de grandes conjuntos habitacionais nos últimos anos, sem o devido cuidado com a contenção do sedimento proveniente do solo exposto pelas obras, fez com que boa parte desse sedimento fosse carregada para dentro do lago. O forte processo de urbanização ao redor de todo o lago também contribuiu para esse fenômeno, uma vez que a pavimentação dificulta a absorção da água das chuvas 
pelo solo, favorecendo o processo de escoamento superficial.

Visando observar esse fenômeno de assoreamento, realizou-se este estudo em áreas previamente selecionadas do reservatório hídrico urbano Lago Paranoá. A seleção da área de estudo no lago Paranoá fundamentou-se nos resultados obtidos por Menezes (2010), o qual promoveu uma análise temporal da área ocupada pelo lago, trabalhando com imagens de sensores LANDSAT e fotografias aéreas, adquiridas entre 1954 e 2009. Essa análise temporal indicou que, dentre as regiões de aporte d'água no Lago Paranoá, aquelas que sofreram maior perda de área foram: a bacia do Ribeirão Riacho Fundo $\left(0,75 \mathrm{~km}^{2}\right)$ e a bacia do Córrego do Bananal $\left(0,07 \mathrm{~km}^{2}\right)$, o que resultou em uma diminuição de $2,2 \%$ da área total do lago. A Companhia de Água e Esgoto de Brasília (CAESB) realizou uma pesquisa em 2003, em que inferia níveis de assoreamento médios de 2,8 metros para o Riacho Fundo e 2,4 metros para o Córrego do Bananal, com base numa comparação de dados topográficos e batimétricos de datas distintas.

\section{Contexto Geológico}

A área de estudos está inserida no Grupo Paranoá: unidade geológica de mais ampla distribuição no DF, ocupando cerca de $65 \%$ de sua área (CAMPOS, 1999). A geologia do DF é formada por uma sucessão de rochas metassedimentares e sua deposição é datada do mesoproterozóico (1.542 a $1.042 \mathrm{Ma}$ ).

Com relação aos solos, é possível distinguir três classes principais no DF: Latossolos Vermelhos (38,63\%) - sua coloração provém do óxido de ferro (Fe2O3) e sua composição granulométrica contém silte (cerca de 20\%) e argila (variando entre 15\% e $80 \%$ ); Cambissolos $(31,02 \%)$ - ocorre principalmente nas vertentes e também nas encostas com alta declividade na depressão do Paraná e bacia do Rio Preto; Latossolos VermelhoAmarelos (15,84\%) - ocorrência quase sempre adjacente aos latossolos vermelhos, geralmente em chapadas, divisores e superfícies planas; (MARTINS et al., 2004).

\section{Metodologia}

As medidas realizadas nesses estudos envolveram parâmetros físicos do meio, como a condutividade, a susceptibilidade magnética, a impedância acústica ou a resistividade elétrica. Foram escolhidos cinco métodos geofísicos distintos para o estudo do assoreamento no Lago Paranoá: i. sísmica; ii. ground penetrating radar (GPR); iii. eletrorresistividade.

\section{Métodos Sismicos:}

Ecobatímetro: Para obter leituras da profundidade do lago, foi utilizado um ecobatímetro hidrográfico da marca ODOM Echotrac CVM de dupla frequência simultânea $(33 \mathrm{kHz}$ e $200 \mathrm{kHz})$ acoplado à embarcação. Os dados foram adquiridos em linhas longitudinais (espaçamento de 25 metros) e transversais (espaçamento de 100 metros) ao curso d'água. O sinal de $200 \mathrm{kHz}$ promove uma resolução maior devido ao seu menor comprimento de onda, porém, sofre maior dissipação. Essa desvantagem é compensada pela maior penetração obtida com o sinal de $33 \mathrm{kHz}$.

Com o intuito de verificar a variação da profundidade nas áreas de estudo, fez-se uma comparação entre os resultados obtidos em 2014 e 2009. A partir da diferença entre essas leituras, fez-se uma estimativa da taxa de sedimentação do período. Os dados foram filtrados e interpolados com o uso dos softwares Hypack Max 2010 e Oasis Montaj Geosoft.

Sonar: utilizou-se um side-scan sonar Edgetech 4100 com sensor piezoelétrico TD272 de dupla frequência (100 e $500 \mathrm{kHz}$ ), acoplado à embarcação, para realizar um imageamento do assoalho lacustre e verificar a sua morfologia. Quando esse equipamento emite um pulso acústio, a maior parte da energia pode ser refletida no fundo do lago de forma homogênea ou, ainda, ser espalhada em diferentes intensidades e direções, no caso de fundos rugosos, afloramentos rochosos, ou na presença de objetos lançados ao fundo do lago (pneus, troncos, entulho etc.). Dessa maneira, a energia que regressa em direção ao sonar é associada à rugosidade, composição e topografia do fundo do lago.

Os dados foram adquiridos segundo perfis orientados WE, espaçados em 25 metros entre si. Os dados foram registados e organizados espacialmente para a construção de uma imagem acústica do leito do lago. As amplitudes foram realçadas por meio de um ganho exponencial nos dados. Esses procedimentos foram adotados por meio do software SonarWiz.

SBP: Utilizou-se o sub-bottom profiller (SBP) Edgetech 3100P com intervalo de frequências de 2 a $16 \mathrm{kHz}$. As camadas geológicas geralmente são identificadas neste equipamento por meio dos contrastes de impedância acústica entre as camadas geológicas. O equipamento é acoplado na proa da embarcação para que a agitação da água (bolhas), produzida pelo motor, não introduza ruído de dados. Camadas com baixo constraste de impedância acústica ou ainda a presença de gás como constituinte de uma dada camada podem representar possíveis fontes de atenuação do sinal sísmico do SBP.

Foram realizados perfis longitudinais ao corpo d’água, espaçados 25 metros entre si, e os dados foram processados com o software SonarWiz.

\section{Método Eletromagnético:}

GPR: O equipamento foi programado para emitir um pulso eletromagnético a cada 250 milisegundos e, considerando-se o deslocamento do barco com 4,5 nós em média, isso proporciona uma leitura a cada 2,5 metros. Com o objetivo de realizar leituras de subsuperfície e identificar a espessura das camadas de sedimentos, fez-se uso da antena GPR Tubewave $100 \mathrm{MHz}$ RadarTeam, acoplada à unidade de controle SIR3000 - GSSI. O GPS Trimble foi ligado ao sistema por meio do Acumen Databridge SDR2-CF. Realizou-se a aquisição de dados segundo perfis longitudinais e transversais ao corpo d'água (espaçados 25 e 100 metros, respectivamente). Os dados foram processados com o software ReflexW (SANDMEIER, 2006). 


\section{Método Elétrico:}

Eletrorresistivímetro: Foi utilizado o eletrorresistivímetro Syscal Pro IRIS conectado ao equipamento Sysmar IRIS e a cabos multieletrodos: $i$. aquático (13 eletrodos de carbono sobre a lâmina d'água); ii. anfíbio (36 eletrodos inox cravados no solo). Os dados de resistividade aparente foram adquiridos segundo três arranjos distintos: Wenner, Dipolo-dipolo e Schlumberger. Cada eletrodo foi espaçado em 5 metros e cada perfil teve espaçamento de 25 metros entre si. Realizou-se uma leitura de resistividade com o arranjo a cada 2 metros deslocados com a embarcação. Para a aquisição de perfis terrestres na margem do lago, utilizou-se o modo estático, também com espaçamento de 5 metros entre os eletrodos.

O sistema de aquisição de dados no barco (cabo aquático) foi acoplado ao GPS Garmin 421S, o qual possui um batímetro monofeixe integrado. A aquisição foi controlada por meio dos softwares Hypack (navegação) Sysmar (armazenamento dos dados).

Realizou-se a coleta de água do lago para análise da condutividade em laboratório, cujo resultado é parâmetro de entrada utilizado durante a modelagem.

A modelagem inversa dos dados de resistividade aparente foi realizada no software Res2DInv. Os valores de resistividade de cada perfil foram postos em um histograma para a classificação das faixas de resistividade.

Com objetivo de perceber variações da ordem de centímetros, um GPS Trimble DSM 232 com correção diferencial via Omnistar HP foi acoplado aos sistemas de aquisição de dados geofísicos da embarcação. Utilizouse como referência de nível a cota de 1000 metros. Garantiu-se o controle sistemático de cotas altimétricas na área com base nas leituras de régua da barragem, fornecidas pela Agência Reguladora de Águas, Energia e Saneamento Básico do DF (ADASA).

\section{Resultados}

Ecobatimetro: Os levantamentos batimétricos realizados em 2013 e 2009 foram comparados, obtendo assim, um grid da diferença desses dados, acompanhado do histograma de comparação entre as leituras batimétricas. Também foram traçados alguns perfis batimétricos para comparação entre os períodos (figura 2). Foram verificadas variações na espessura de até $0,80 \mathrm{~m}$ em boa parte da área. A variação média da área foi de 0,348 metro,com máximo de 1,3 metros e mínimo em -0,78m para o Córrego do Bananal. Assumindo o valor médio da área, distribuídos pelo período entre as duas pesquisas batimétricas, foi possível realizar uma estimativa preliminar da taxa de sedimentação em 6,97 cm/ano para o Córrego do Bananal

É importante notar que existem áreas onde houve deposição, mas na margem oeste houve um aumento na profundidade, trecho onde o córrego segue preferencialmente. As acumulações de sedimentos se deram tanto na foz do córrego Bananal (norte) quanto mais a sul do mapa, onde fica a galeria de águas pluviais que conecta o Lago Paranoá a um novo setor habitacional, o bairro Noroeste.

Sonar: O sonar de varredura lateral possibilitou a obtenção dos mapas de fundo das áreas de estudo do Lago Paranoá. Foi possível identificar alguns padrões de reflexão do sonar, os quais foram relacionados a tipos de materiais distintos depositados no assoalho do lago (figura 3). As superfícies que refletem sinal acústico do sonar são descritas como refletores especulares ou superfícies difusoras: diferentes padrões de retorno da onda sonora, refletida no fundo lacustre em diferentes condições de rugosidade e contraste de impedâncias acústicas entre solo e água, permitem inferir sobre a composição granulométrica. A intensidade do eco acústico em conjunto com características texturais da imagem de fundo caracterizaram bem 0 assoalho lacustre na área de estudos. Isso permite a localização de regiões de acúmulo de sedimentos, marcas de talude e a presença de objetos lançados no lago, como tubulações, pneus, troncos, entulho etc.

Perfilador: Os dados obtidos com o SBP evidenciaram uma forte atenuação do sinal sísmico. Não houve penetração ou resolução suficiente para que fosse possível caracterizar a espessura do sedimento de fundo do lago.

Em campo, foi notada a presença de gás no sedimento, cujo módulo de compressão é muito baixo quando comparado com a água, alterando o comportamento do módulo de compressão total da camada de sedimentos. Isso ocasiona a redução da velocidade de propagação do sinal acústico, o que explicaria a atenuação do pulso do SBP.

GPR: Não houve penetração suficiente para caracterizar com clareza a espessura do pacote sedimentar do leito com o GPR. Ainda assim, alguns trechos do perfil apresentaram evidências da presença da camada de sedimentos. A forte presença de gás no sedimento, na forma de bolhas, provoca uma dissipação do sinal (devido às difrações que ali ocorrem), atenuando muito a resposta do radar. Além disso, deve-se levar em consideração a alta condutividade elétrica da camada de sedimentos mais superficial do lago, que é bastante argilosa. Essa grande variação dos parâmetros físicos provoca uma perda no percentual de energia que retorna à antena receptora do GPR.

Eletrorresistividade: As seções de eletrorresistividade 2D foram obtidas por meio da inversão de dados de resistividade para cada um dos arranjos, em separado. $O$ valor da condutividade da água, no Córrego do Bananal, obtido no teste de laboratório foi de $82 \mu \mathrm{S} / \mathrm{cm}(120 \Omega / \mathrm{m})$. Em seguida, foi feito um histograma para classificar as resistividades segundo intervalos de valores atribuídos a cada tipo de material (sedimento, solo, rocha). As seções interpretadas, para os cabos aquático e anfíbio, são apresentadas nas figuras 4 e 5 . 
É importante ressaltar que nas regiões mais assoreadas (parte mais à montante dos tributários) não foi possível navegar, uma vez que grandes acumulações de sedimentos impossibilitavam 0 acesso com a embarcação (profundidades abaixo de 50 centímetros).

\section{Discussão e Conclusões}

Alguns dos métodos geofísicos utilizados neste trabalho mostraram-se bastante eficientes para a caracterização das regiões de acúmulo de sedimentos nas áreas de estudo. Outros, porém, foram ineficientes em função de algumas características físicas dos sedimentos do fundo do lago.

A batimetria se mostrou bastante eficaz nesse tipo de estudo, principalmente quando são realizados levantamentos periódicos, pois é possível acompanhar com boa precisão a evolução do aporte de sedimentos, bem como realizar uma estimativa da taxa de sedimentação. Para a área do Córrego do Bananal, a taxa estimada foi de $6,97 \mathrm{~cm} /$ ano.

O side-scan sonar mostrou eficiência no mapeamento do leito e análise da geomorfologia do assoalho lacustre em função desse método trabalhar com as impedâncias acústicas superficiais. Foi possível identificar padrões distintos de reflexão do pulso acústico e associá-los a diferentes tipos de refletores.

$\mathrm{O}$ SBP, com frequência de operação de 2 a $16 \mathrm{kHz}$, mostrou-se ineficiente no estudo do assoreamento dessa região em função da imensa atenuação do sinal acústico em subsuperfície, causada pelo baixo contraste de impedância entre os meios. Talvez outras frequências se mostrem mais adequadas para imagear a subsuperfície.

O GPR não possibilitou o imageamento de interfaces sedimentares com clareza devido à alta condutividade da camada de sedimentos. Os dados da resistividade da camada superficial colaboram para essa interpretação. Essa camada contém sedimentos finos (argilosos) e matéria orgânica, o que contribui para a elevada condutividade detectada. É possível que antenas de menor frequência possam apresentar resultados mais satisfatórios.

A eletrorresistividade mostrou-se eficiente na determinação da camada sedimentar mais rasa, alvo desse estudo. Nos dados adquiridos com o cabo aquático, verificou-se, no Córrego do Bananal, uma camada sedimentar variando entre 1,5 e 2,5 metros de espessura.

Os dados de eletrorresistividade com o cabo anfíbio foram interpretados tendo como base um modelo de três camadas, porém os resultados não tiveram a mesma correlação com o modelo esperado quando comparados com os resultados obtidos com o cabo aquático. Todavia, usando-se um espaçamento menor, espera-se obter melhores resultados com esse cabo e, assim, detalhar os pacotes sedimentares mais delgados.

Com base nesses resultados, pode-se elaborar uma tabela de avaliação e recomendação, dentre os métodos geofísicos utilizados, dos métodos mais recomendáveis para este tipo de estudo ambiental (tabela 1).
Tabela 1 - Avaliação dos métodos geofísicos neste trabalho.

\begin{tabular}{|c|c|c|}
\hline MÉTODO & DESEMPENHO & AVALIAÇÃO \\
\hline Batimetria & $\begin{array}{c}\text { A comparação de } \\
\text { resultados a levantamentos } \\
\text { batimétricos de períodos } \\
\text { distintos possibilitou uma } \\
\text { estimativa de taxa de } \\
\text { sedimentação média. }\end{array}$ & Muito bom \\
\hline Sonar & $\begin{array}{c}\text { O resultado obtido permitiu } \\
\text { a identificação de regiões } \\
\text { de acúmulo de sedimentos, } \\
\text { bem como a identificação } \\
\text { de objetos lançados no lago } \\
\text { e marcas de talude. }\end{array}$ & Muito bom \\
\hline SBP & $\begin{array}{c}\text { O sinal foi fortemente } \\
\text { atenuado pelo sedimento } \\
\text { devido a presença de gás }\end{array}$ & Ruim \\
\hline GPR & $\begin{array}{c}\text { Forte atenuação do sinal } \\
\text { em função a alta } \\
\text { condutividade do sedimento } \\
\text { e a presença de gás. } \\
\text { Feições pouco perceptíveis. }\end{array}$ & Razoável \\
\hline Resistividade & $\begin{array}{c}\text { Foi possível realizar uma } \\
\text { distinção entre camadas em } \\
\text { subsuperfície em função de } \\
\text { suas resistividades. }\end{array}$ & Muito bom \\
\hline
\end{tabular}

Portanto, neste estudo os métodos geofísicos que apresentaram maior eficiência foram: i. batimetria; ii. sidescan sonar; iii. eletrorresistividade. Para que seja realizado um acompanhamento minucioso do aporte de sedimentos, recomenda-se a realização de levantamentos geofísicos sistemáticos com esses métodos. A correlação desses resultados com dados de sensoriamento remoto e testemunhos de sondagem também são altamente recomendáveis.

\section{Agradecimentos}

Agradecemos ao Laboratório de Geofísica Aplicada da UnB (LGA/UnB), aos técnicos da UnB Péricles e Mendes, ao Corpo de Bombeiros do DF, ao Batalhão Ambiental da Policia Militar do DF e a Phygeo, empresa júnior de geofísica da UnB, pelo auxílio prestado durante a etapa de aquisição dos dados desta pesquisa.

\section{Referências}

ADASA, Agência Reguladora de Águas Energia e Saneamento Básico do Distrito Federal. Norma Técnica: Resolução ADASA nำ 14/2012 - Estabelecimento de níveis altimétricos da água a serem mantidos no Lago Paranoá, no ano de 2013. Brasília - DF, 2012. Disponível em<http://www.adasa.df.gov.br/images/stories/anexos/Co tas_LP/2013/Res_14_2012_Cota_LP2013.pdf> Acesso em: 10 de julho de 2013 .

CAESB, Companhia de Água e Esgoto de Brasília. Plano de Gestão e Preservação do Lago Paranoá: Produto 1 - 
Levantamento, Caracterização e Situação atual. Brasília - DF, 2003.

CAMPOS, J.E.G. (2004) Hidrogeologia do Distrito Federal: Bases para a gestão dos recursos hídricos subterrâneos. Revista Brasileira de Geociências, Volume 34(1): 41-48, março de 2004.

CARVALHO, N. O. Hidrossedimentologia Prática. 1 ed. Rio de Janeiro: Serviço Geológico do Brasil - CPRM, 1994.

CARVALHO, N. O.; Santos, P. M. C. et al. Guia de Avaliação de Assoreamento de Reservatórios. Brasília: Agência Nacional de Energia Elétrica, Superintendência de Estudos e Informações Hidrológicas. 132p. 2000.
ICOLD, International Commission on Large Dams Sedimentation control of reservoirs/Maîtrise de l'alluvionnement des retenues. Committee on Sedimentation of Reservoirs. Paris. 1989.

MENEZES, P. H. B. J. Avaliação do efeito das ações antrópicas no processo de escoamento superficial e assoreamento na Bacia do Lago Paranoá. Dissertação de Mestrado - Universidade de Brasília - UnB, Brasília-DF. 133p. 2010.

NICHOLS, G. Sedimentology and Stratigraphy 2ed. Oxford: Ed.Wiley-Blackwell. p. 419. 2009.

SUGUIO, K. Geologia Sedimentar. São Paulo: Ed. Edgard Blucher. 416 p. 2003.

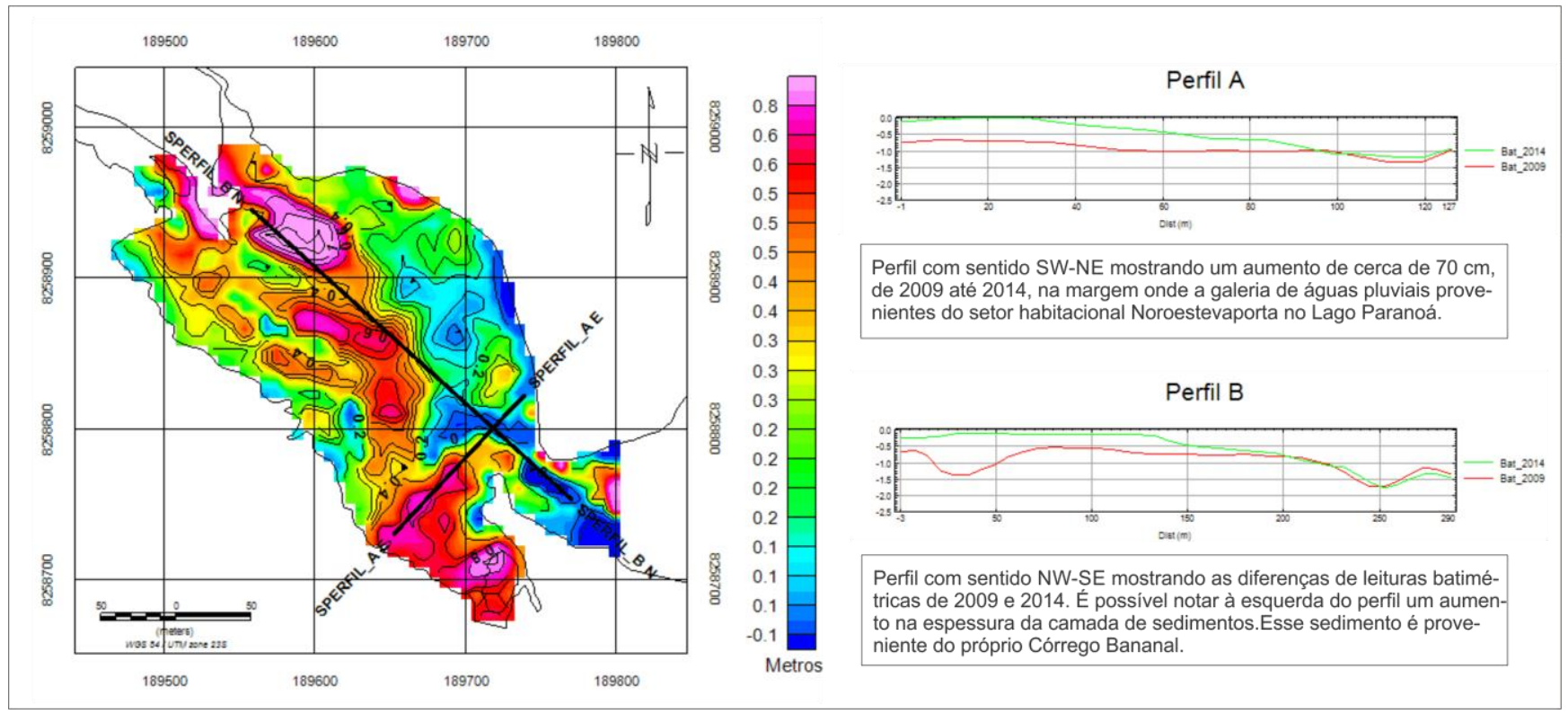

Figura 2 - Mapa batimétrico da diferença entre as leituras de 2009 e 2014. No detalhe os, perfis batimétricos mostrando o acréscimo de material depositado no leito do Lago Paranoá. 


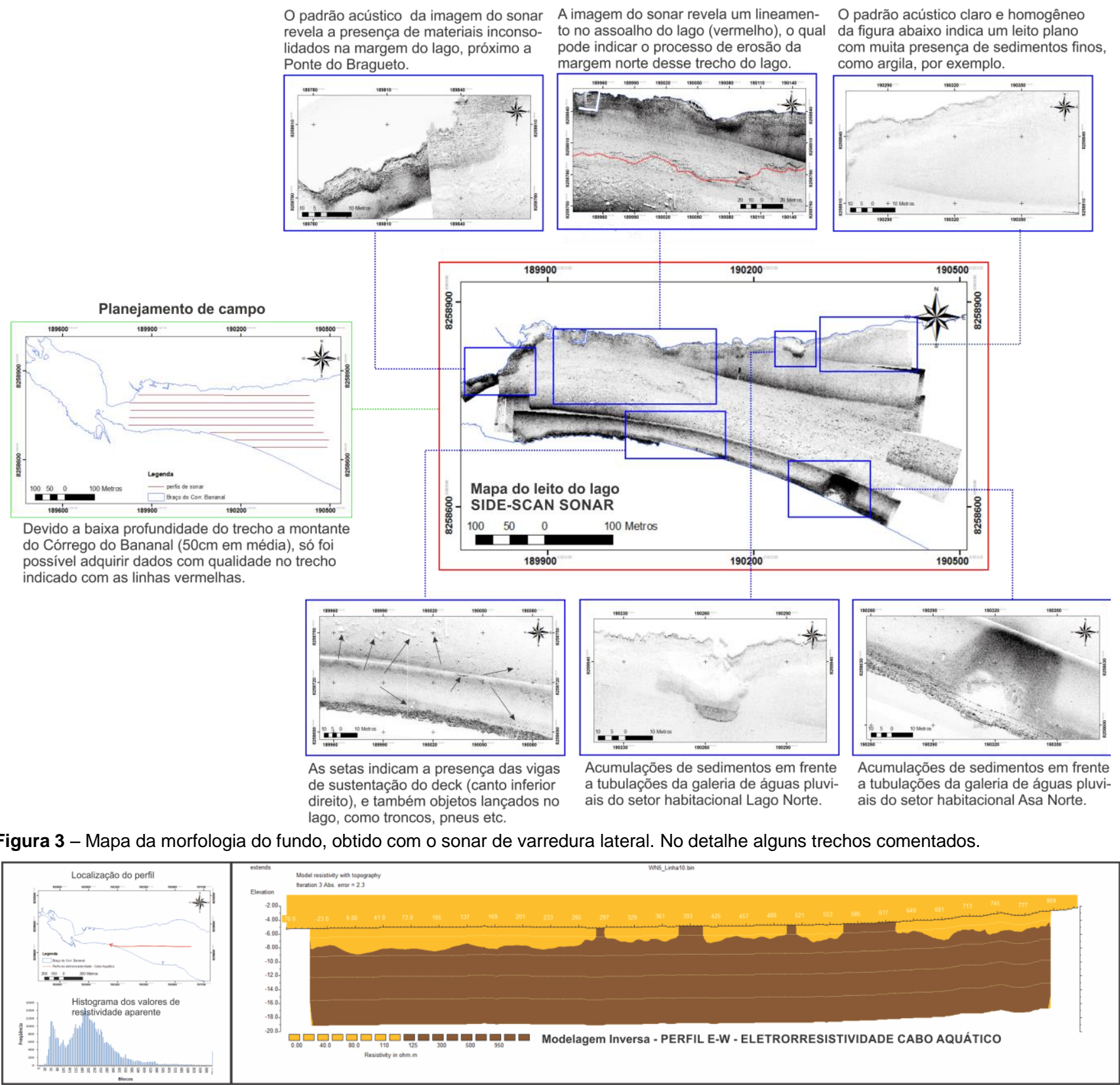

Figura 4 - Perfil de eletrorresistividade obtido com o cabo aquático. No detalhe, a figura mostra a localização do perfil e o histograma dos valores de resistividade aparente desse perfil. Com esses valores, foi possível separar os valores de resistividade em duas faixas, sendo estas realizadas com base em um modelo geológico simples de 2 camadas: sedimento e embasamento.

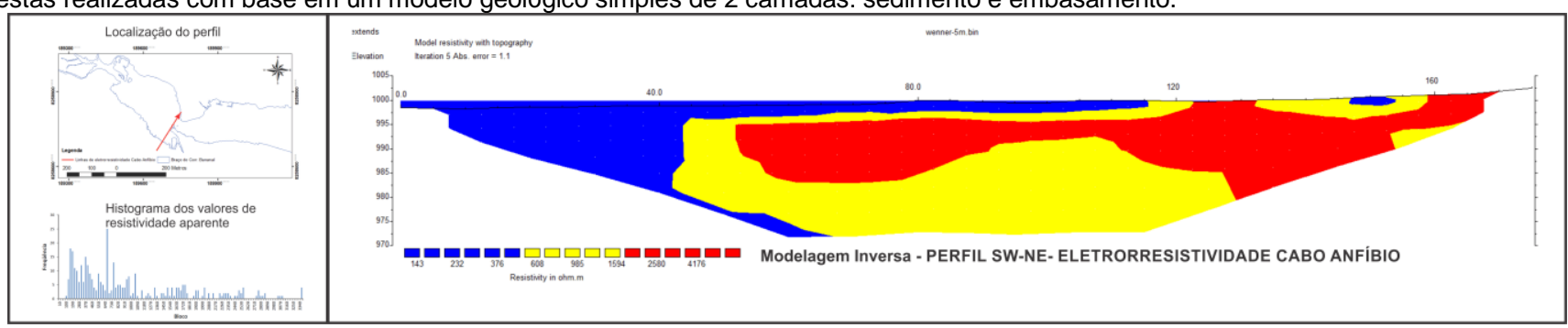

Figura 5 - Perfil de eletrorresistividade obtido com o cabo anfíbio. No detalhe, a figura mostra a localização do perfil e o histograma dos valores de resistividade aparente desse perfil. Com esses valores, foi possível separar os valores de resistividade em duas faixas, sendo estas realizadas com base em um modelo geológico de 3 camadas: solo, embasamento e sedimento do lago. 